\title{
LATINX STUDENTS IN THE GTA AND SURROUNDINGS AND HIGHSCHOOL DISENGAGEMENT
}

by

Catalina Calero, BSW, University of Waterloo, 2016

\author{
An MRP \\ presented to Ryerson University \\ in partial fulfillment of the \\ requirements for the degree of \\ Master of Social Work \\ in the Program of \\ Social Work
}

Toronto, Ontario, Canada, 2017

(C) Catalina Calero 2017 


\section{AUTHOR'S DECLARATION FOR ELECTRONIC SUBMISSION OF A MRP}

I hereby declare that I am the sole author of this MRP. This is a true copy of the MRP, including any required final revisions.

I authorize Ryerson University to lend this MRP to other institutions or individuals for the purpose of scholarly research

I further authorize Ryerson University to reproduce this MRP by photocopying or by other means, in total or in part, at the request of other institutions or individuals for the purpose of scholarly research.

I understand that my MRP may be made electronically available to the public. 


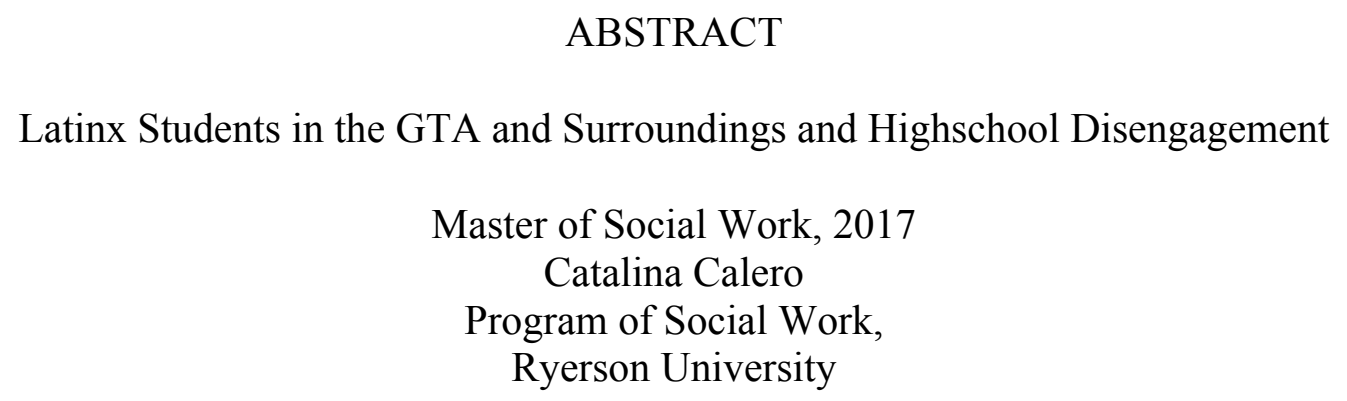

My focus in this study is to explore the experiences of former Latinx/a/o high school students and their view on the factors that led them to either graduate or "dropout" of high school. I am also interested in better understanding their experiences with social workers in schools and how social workers can better support students. Using a narrative approach, I center the voices and experiences of my participants. I gathered these experiences in a focus group, and through thematic analysis I analyzed these findings in relation to the existing literature. With this study, I hope to contribute to the current academic literature on this subject, and would also like to extend the work that has been done in the community with the hopes of further analysis and response on the issue of "low academic achievement" of Latinx/a/o students. 


\section{ACKNOWLEDGEMENTS}

I would like to acknowledge my research participants, and thank them for sharing their experiences with me and all those who read this paper, and for their role in helping bring forward the voices and experiences of Latinx students in Toronto and GTA.

I would also like to use this opportunity to acknowledge some of the individuals who have provided me with tremendous support and mentoring throughout my schooling journey. Francisco Villegas, Andrea Vásquez Jiménez and Derik Chica, thank you for believing in me! 


\section{DEDICATION}

I dedicate this work to my parents, who have always supported me in every way. I would not have made it to where I am today without them. Thank you for your undying love and for teaching me to never give up. 


\section{TABLE OF CONTENTS}

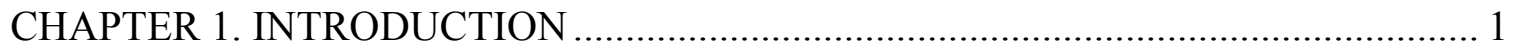

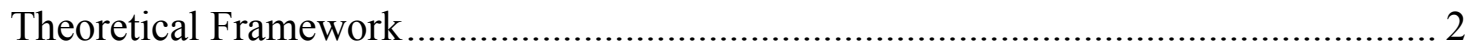

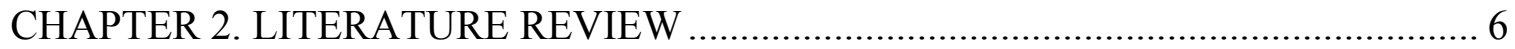

Availability/Accessibility of Programs and Resources.................................................. 6

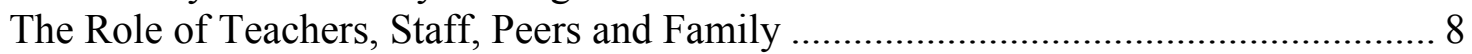

Othering and the Eurocentric School Climate …………............................................. 10

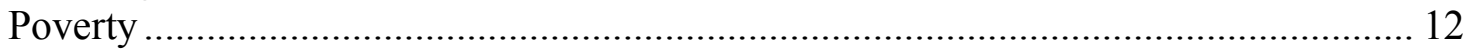

Cultural Values/Identity and Self-Perception ........................................................ 12

Community Responses \& Resistance ……………................................................... 14

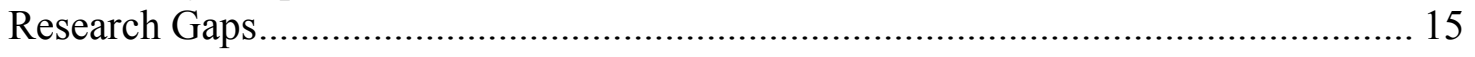

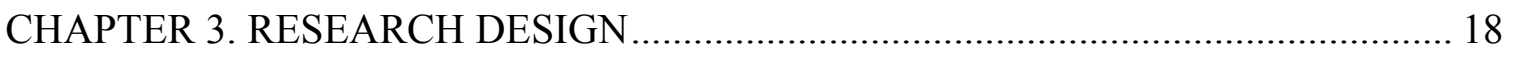

Participants \& Recruitment.............................................................................. 19

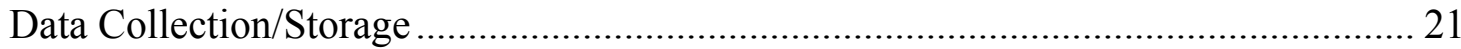

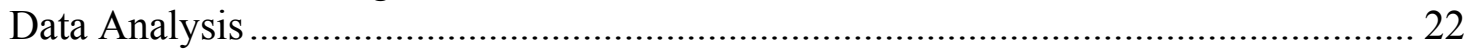

CHAPTER 4: FINDINGS AND DISCUSSION ………………………………..... 23

The Role of Teachers, Staff, Peers and Family ........................................................ 23

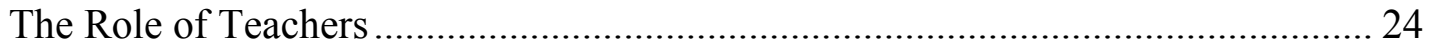

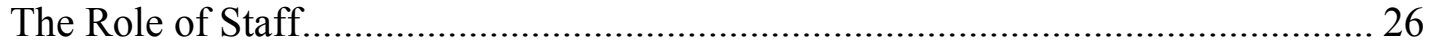

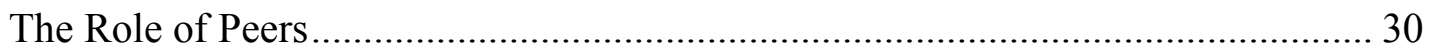

The Role of Parents and Family............................................................................... 32

Access to Programs and Resources......................................................................... 34

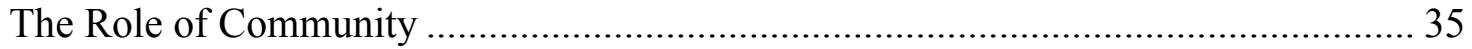

Othering and Eurocentric School Climate ................................................................. 37

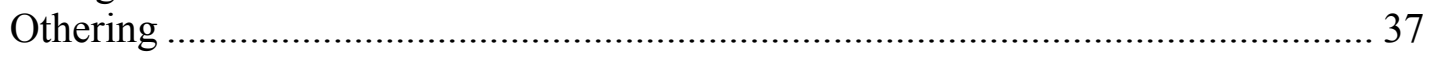

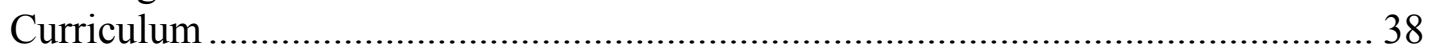

Identity, Self-Perception and Mental Health ........................................................... 39

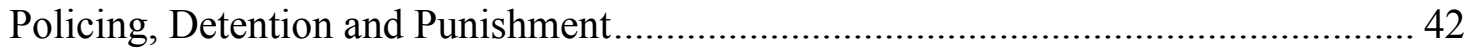

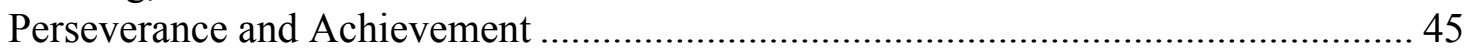

CHAPTER 5: IMPLICATIONS AND CONCLUSION …………………………..... 47

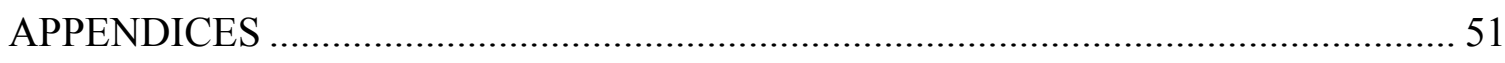

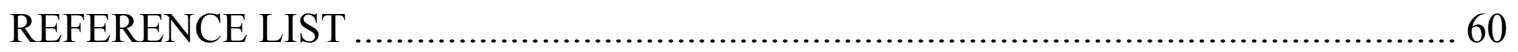




\section{LIST OF APPENDICES}

Appendix A - REB Approval 51

Appendix B - Recruitment Flyer 52

Appendix C - Recruitment Email 53

Appendix D - Consent Agreement 54

Appendix E - Focus Group Interview Guide 59 


\section{CHAPTER 1. INTRODUCTION}

The student body of the Toronto District School Board (TDSB) reflects the vast ethnic diversity of its city. Unfortunately, not all ethnic groups have been able to achieve academically as well as others, with higher percentages of high school students from certain ethnicities not making it to graduation. According to The TDSB Grade 9 Cohort Study: A Five-Year Analysis, $2000-2005$, in Toronto, the general "drop-out" rate from high school is $23 \%$, compared to almost $40 \%$ among the Spanish-speaking students (Schugurensky, 2009). This issue is important to study and of particular relevance to social work because of the personal and social consequences of "dropping out" of school. Not only does less schooling lead to lower income, but it also affects the social position of lower income individuals and their families by limiting the resources available to them over time and their possibility of moving out of poverty (Altonji \& Doraszelski, 2005). Further, the level of educational attainment is recognized as a social determinant of health by increasing options and resources for physical and mental health (Shankar, et al., 2013). For example, since post-secondary education is now a common minimum requirement to secure employment (Shankar, et al., 2013), low educational attainment, low income and lack of opportunities for an individual and their family then also lead to an array of social and health related problems affecting their overall wellbeing. This MRP explores the topic of educational attainment by looking specifically at the experiences of Latinx students, described further below.

Here, it is important to note a couple of things. First, that the makeup of Spanishspeaking students in the TDSB is itself very diverse, encompassing newcomers, first and second generation Canadians, with families originating from many different countries in South and Central America (including Mexico). Also, individuals of the Latin American diaspora do not 
fall under defined racial categories, but belong to a spectrum of ethnicities and nationalities (Lynn \& Dixson, 2013). Secondly, in the following paper I will be using the term Latinx when referring to this community. The " $\mathrm{x}$ " in Latinx makes the word a gender-neutral identifier (Reichard, 2015), instead of using the masculine/feminine a/o. This has been a growing and accepted change in language in activist and scholarly communities in an effort to be more inclusive of gender non-conforming individuals.

This topic is not only relevant to social work but very personal to me. Identifying as a Latina, and having experienced a difficult path through education to where I finally am todayaccomplishing my dream of completing a Masters of Social Work- I have a personal connection with the topic of academic success within my community here in Toronto.

\section{Theoretical Framework}

The theoretical approach that is informing my understanding of this issue is a combination of Critical Race Theory (CRT) and LatCrit Theory. I will first explain each of these theories, their relevance to my research and the concepts I will be using, then will demonstrate why I have chosen to use these particular theories together.

According to Crenshaw, Gotanda, Peller, and Thomas (1995), "Critical Race Theory challenges the universality of white experience and judgement as the authoritative standard that binds people of color and normatively measures, directs, controls, and regulates the terms of proper thought, expression, presentment, and behaviour.” (pg.318). CRT has a strong legal foundation, originating from the field of legal studies in the 1970's (Museus, 2013), and surfacing out of the realization of civil rights lawyers and scholars that "new tools were needed to deal with the insidious forms of institutional or veiled racism that were developing and an American public that seemed tired of hearing about race" (Lynn \& Dixson, 2013, p. 25). Therefore, CRT provides a framework with which to analyze the way racism plays out within 
institutions, and attempts to bring the subjugated knowledges and experiences of racialized individuals to the forefront.

CRT is very relevant to education because it supports an understanding of school inequality (Lynn \& Dixson, 2013). Further, in relation to research on education, a CRT approach “...can be used to question the variables chosen (or ignored) in quantitative research as well as establish- counter narratives in qualitative research" (Lynn \& Dixson, 2013, pg.21). As previously stated, CRT came out of the desire to examine and critique the legal system in how it was (not) serving people of color (Crenshaw, Gotanda, Peller, \& Thomas, 1995), and in the context of my research, CRT is applied to the education system and how it has (not) served Latinx peoples. CRT poses challenges to dominant discourse with regards to race, and in this context would look at how education as an institution subordinates certain ethnic groups (Solorzano \& Yosso, 2001).

Similar to, and branching out of CRT, LatCrit started by using narrative storytelling to analyze how race, ethnicity, language and national origin interlock to "other" Latinxs in the United States (Lynn \& Dixson, 2013). In the education context, LatCrit also uses histories, research and counter-stories of Latinx peoples to examine how race and racism influence the educational structures, processes, and policies that in turn affect Latinx students through for example, experiences of micro and macro aggressions. Further, there is a large focus on social justice and action, and an emphasis on praxis (Lynn \& Dixson, 2013). LatCrit addresses issues such as language, immigration, ethnicity, culture, identity, as well as others that are not commonly addressed by CRT, and brings to light the multidimensional aspects of the identities of the Latinx diaspora (Solorzano \& Bernal, 2001). 
Of specific relevance to this MRP are the following concepts from CRT and LatCrit: narrative or stories/ storytelling, intersectionality, challenge to dominant ideology, centrality of experiential knowledge and avoidance of deficiency discourses.

Lynn \& Dixson (2013) remind us that the oral tradition of storytelling used by ancient cultures enabled them to maintain their histories and cultural sense of self. This points to the value of narrative and storytelling and their impact on an individual's sense of self. Stories can also be very powerful, as they reflect perspectives or points of view and emphasize the beliefs and values of the narrator, audience, society, and/or those in power (Lynn \& Dixson, 2013). Further, oppressed individuals have valuable knowledge which have the ability to counter dominant hegemonic narratives of themselves and the world around them (Museus, 2013).

Another key concept is intersectionality refers to the way that race, class, gender, sexuality, ability, and other parts of an individual's identity combine to create and influence an individual's experiences of oppression (Museus, 2013). This is relevant and important for my topic because an intersectional approach allows us to examine the complexities of the lived realities of oppressed individuals. In the context of the student experience, considering intersectionality enables a deeper analysis of the various ways different forms of oppression play out in the institutional and everyday school context.

One of the central concepts of CRT is the challenging of dominant ideologies such as meritocracy, colorblindness, race neutrality and equal opportunity (Museus, 2013) which tend to portray individuals as completely autonomous and reality as an even playing field. In an education context, it is challenging the narratives of the abilities of racialized students and Eurocentric standards of academic achievement (Lynn \& Dixson, 2013). 
Furthermore, the life experiences of people of color not only constitute legitimate knowledge but are also valuable tools that can be used to analyze racial oppression (Museus, 2013). Part of challenging dominant ideologies is the surfacing and centering of this experiential knowledge and one way that subjugated knowledges are brought to light are through the use of storytelling or the use of personal narratives. Centering these narratives places emphasis on the wealth of knowledge that youth can bring to their education. These stories can also hen be used to examine the way individuals experience oppression on a daily basis.

Finally, another concept is the avoidance of deficiency discourses (Gloria LadsonBillings, 2007; Solorzano \& Yosso, 2001). Related to education, this means avoiding explanations of the high dropout rate that depict Latinx students, their families and their cultures as deficient. Success and failure among students are a result of processes that contribute to this rather than being a personal problem or deficit (Ahmed, 2007). Further, Gloria Ladson-Billings (2007) urges us to get away from deficit thinking such as the following explanations for “achievement gaps": the parents don't care, families don't value education, or they are coming from a culture of poverty.

I have chosen to use both CRT and LatCrit Theory because the combination of concepts together create a thorough framework that includes applicability to the education system; relevance to racialized communities and specifically Latinx individuals; and valuing of the experiences of these students. Further, this framework will enable me to deconstruct existing dominant stories of the Latinx "school dropout". 


\section{CHAPTER 2. LITERATURE REVIEW}

In reviewing the literature, I consulted relevant social work databases and focused on the following journals: The Journal of Negro Education (2), Hispanic Jounral of Behavioural Sciences (3), Journal of Adolescence, Canadian Review of Sociology, Sociology of Education, English Quarterly, Journal of Hispanic Higher Education, Education and Urban Society, Latin American Encounters, Gender and Society, Journal of Cases in Educational Leadership, International Journal of Environmental Research and Public Health, urban education, American Educational Research Journal, I also relied on the following keywords: Latina/Latino/Hispanic students, academic success, disengagement, dropout, early school leaving.

The main themes I have encountered in the scholarship related to early school leaving are the availability/accessibility of programs and resources; the role of teachers, staff, peers and family; othering and the Euro- centric school climate; poverty; cultural values/identity and selfperception; and community responses. Following a presentation of these themes, I will conclude this section with a discussion on the knowledge and knowledge construction around this issue, and the gaps in this literature.

\section{Availability/Accessibility of Programs and Resources}

A substantial amount of literature has pointed to the importance of programs and resources in the academic success of racialized and Latina/o students (Behnke, Gonzalez, \& Cox, 2010; Dei, et. al., 2010; Harris \& Kiyama, 2015; Matute \& Chica, 2014; Walker, 2006). Community based programs have the potential to be safe spaces that foster mutual trust with school and community adults, as well as assist students in navigating the school system (Harris \& Kiyama, 2015). According to Harris and Kiyama, this trust and social support then enables academic support to be provided by these adults such as parents, teachers and community members who act as "institutional agents". Even when these programs are in place, it is 
important to consider the accessibility of these supports. For example, a high school-based program in the United States, Upward Bound, provided tutoring over the phone after school hours, and helped students that otherwise would not have access to tutoring after school (Harris \& Kiyama, 2015). This is an example of how school and community based programs can aid Latinx high school students to stay in school.

Hence, a lack of these supports and programming is linked to early school leaving, as voiced by students (Behnke, Gonzalez \& Cox, 2010; Matute \& Chica, 2014) as well as community members and educators (Matute \& Chica, 2014). For example, Behnke, Gonzalez and Cox (2010) looked for Latinx students' perspectives as to why their peers were dropping out, and their study consisted of in-depth surveys with 501 Latinx students from public schools throughout North Carolina. Students reported that some of the reasons were the difficulty of their school work and personal problems, among other things, which perhaps reflects a lack of supports such as tutoring and spaces such as the above-mentioned community programs where students can receive various forms of guidance from institutional agents.

A study that looked at the conceptions of "success" and "failure" held by high academic achievers of various ethnic backgrounds concluded that every student is capable of success given the right tools and resources (Dei, et al., 2010). This suggests that availability of resources plays a larger role in success than personal "deficit". Further, studies have concluded that peers can also be a significant resource for each other: a study that looked at mathematics success of Black and Latinx youth found that classmates who did well served as resources for other students in studying and understanding math (Walker, 2006). This points to the importance of creating spaces where students can build community to support each other and share resources; such spaces can be an integral part of school and community led programming for students. 


\section{The Role of Teachers, Staff, Peers and Family}

A positive connection has been found with the ability to relate to teachers and staff linguistically and/or ethnically and the academic success of Latin American students (Behnke, Gonzalez \& Cox, 2010; Dei et al., 2010; Harris \& Kiyama, 2015; Matute \& Chica, 2014). Harris and Kiyama's (2015) study concluded that the students' negative experiences were in part due to a lack of qualified bilingual (Spanish/English) teachers, while Behnke, Gonzalez, and Cox (2010) found that students felt they would benefit from more Spanish speaking staff and teachers. Further, teachers of similar racial backgrounds have been found to be essential in student success (Dei et. al., 2010; Matute \& Chica, 2014) as they can be role models for students from disadvantaged backgrounds (Dei et al., 2010).

On the other hand, regardless of linguistic or racial background, there are still ways to keep students engaged and motivated. Adkins-Coleman's (2010) study looked at the experiences of two teachers from an urban school and found that when teachers genuinely care for their students and demonstrate this through creation of a caring class community, it has a huge positive effect on student motivation, engagement and learning. The expectations that teachers have of their students also have a large impact on them. For example, Rodriguez (2011) found that teachers in an elementary school had low expectations of their Mexican American and immigrant students which hindered their ability to adequately prepare students for their transition to middle school or to meet state standards through testing. These low expectations were based on deficiency oriented beliefs of their students based on their low English proficiency and socioeconomic status (Rodriquez, 2011). Walker (2006) also found that the high achieving students in their study perceived high expectations from their teachers and parents. It is 
important though to have a balance between high expectations, and understanding and support, as some students need to juggle family responsibilities with school work (Espinoza, 2010).

Matute and Chica (2014) also found that lack of support in schools was a common theme at a Latin American Education Forum in Toronto when educators discussed the challenges faced by their students in the education system. Another study looked at the relationship between the academic support provided from parents and teachers and the academic motivation of Latinx youth, finding that the more academic support the youth received in the $9^{\text {th }}$ grade, the higher their academic motivation (Alfaro \& Umana-Taylor, 2015). However, the relationship was not as clear for the following years, which is an indication that academic support alone is not a sufficient determinant of motivation; and a more comprehensive study would look at a variety of environmental and systemic variables. For example, Walker (2006) found that even though some parents did not complete high school, their encouragement, expectations and "lost dreams" were very strong motivators for the students. On the other hand, as mentioned earlier, parental expectations of family responsibilities may hinder students' abilities to complete school work (Espinoza, 2010). However, Espinoza (2010) focuses on the familial aspect of these conflicting responsibilities and does not look at the structural influence or conditions that create the need for students to assist family while in school, or the narrow perspective of the education system which places school work completion as a higher priority than family responsibilities.

Peers and close friends who shared interests and school related goals were found to have a positive effect on students' academic success. When looking at mathematics success of Black and Latinx youth, Walker (2006) demonstrated that academic communities created among peers are effective in supporting the achievement of minority students, and that students are capable of creating and sustaining these communities. 
Principals are also in the position to play a positive role in the improvement of Latinx students' experiences in the education system. Rodriguez' (2011) case study demonstrated that adjusting school programing and challenging teachers to better serve their students as well as to question their negative perceptions of students can create positive change. When the principal facilitated an informal gathering of teachers with students and their families, this not only opened the line of communication between parents and teachers, but allowed teachers to better understand and appreciate their students' environment, family life and culture, which served to dispel much of their negative preconceived notions. Further, this professional development for teachers also emphasized high expectations and challenging activities for students (Rodriquez, 2011). However, since this study was carried out in the United States, the role of principals might be different in a Canadian context, based on their job descriptions and limitations. Despite this, Matute and Chica (2014) also found that it was necessary to improve staff practices and training, and that school boards in Toronto could improve communication with families and community as well as support research that would further inform the discussion on possible solutions. This all points to the importance of involvement and communication of school administration, staff and parents in the academic success of minority students.

\section{Othering and the Eurocentric School Climate}

Othering through racism, micro-aggressions and discrimination negatively affect academic success and there are many studies that point to the negative consequences of these experiences, from teachers, peers, and school staff (Alfaro et. al., 2009; Carter, 2006; Rodriguez, 2011) and in particular, for boys (Alfaro et al., 2009). Matute and Chica (2014) confirm these findings, with stereotypes and prejudice as a common challenge voiced in the community discussions at the education forum. The negative perception that some teachers/staff have of their students can also be considered a form of othering when students are treated differently through 
lowered expectations when they are not seen as fitting in or achieving within the typical Eurocentric structure of schooling (Rodriguez, 2011).

The euro-centricity of the school curriculum and classroom have a large role to play. A study by Shankar et. al (2013), which explored the education experiences of Canadian youth from low income Indigenous and visible minority backgrounds, found that the Eurocentric format of education delivery and focus on written assignments did not meet the needs of these students. Similarly, Dei (2010) found that the euro-centricity of the Ontario school system is problematic for students because of its inability to give a well-rounded view of the world. This points to the need for the experiences of learners to be placed at the centre of their education, as well as the role of diversity in knowledge production to challenge dominant ways of knowing (Dei, 2010).

Further, Carter (2006) looked at the concept of "acting white" and found that contrary to popular belief, not all Black and Latinx students define "acting white" as a rejection of schooling and high achievement, but rather, as a way to assert their own cultural styles that are usually not considered congruent with achievement and mobility, and a refusal to adhere to the default white American cultural setting in society. Carter (2006) concluded from their study that schools that incorporate practices that promote inter-culturalism can possibly have more positive academic and social effects among minority students than schools that do not.

Finally, for Latinxs who are newcomers to Canada or United States, there are challenges which are unique to them and different from their Canadian or American-born counterparts. For example, navigating the language barrier and the unique identity issues that come with migration to a new country, which overall pose additional challenges for parents and youth when navigating the education system (Matute \& Chica, 2014). 


\section{Poverty}

Research by Anisef, Brown, Phythian, Sweet, and Walters (2010) examined the results of a TDSB study that tracked a single grade nine cohort for six years. The authors found that students living in poorer neighbourhoods had higher dropout rates. This is relevant because high numbers of immigrant youth live in poor neighbourhoods (Anisef, Brown, Phythian, Sweet, \& Walters, 2010), and many Latin American youth are newcomers or from newcomer families. Another study also made the connection between poverty and academic achievement, finding that many students dropped out due to the need to work in order to support their family financially (Behnke, Gonzalez, \& Cox, 2010). Taking care of siblings was the most common family expectation in Espinoza's (2010) study, which can be attributed to the absence of parents who are either working evenings or cannot afford day care.

On the other hand, Carter's study (2006) found that despite being from low income families, many Black and Latinx youth had high aspirations, valued education and believed that it paid off in the future. Most of the students (84\%) aspired to continue on to postsecondary schooling and more than half $(60 \%)$ had a desire to eventually hold a professional/managerial/high level job, such as a physician, lawyer or businessperson (Carter, 2006).

\section{Cultural Values/Identity and Self-Perception}

Cultural values and identity have been found to impact student experiences and choices related to education (Espinoza, 2010; Matute \& Chica, 2014; Ovink, 2014). A cultural value that is common to Latin American people is "familismo" which refers to the privileging of family interests above those of the individual. Some students experience tension between family and individual interests, in particular when educational institutions do not acknowledge or legitimize the family responsibilities students have that may interfere with school work, and when the 
expectation is to prioritize school; further, the literature shows that balancing these demands is a learning process (Espinoza, 2010).

Familismo can also be experienced differently depending on gender, where women feel more pressure and lack of autonomy than men (Ovink, 2014). This “gendered familism”, was found to affect the college choices of Latinxs: Latinas sought four year degrees as a way to earn their independence, whereas Latinos already felt a strong sense of autonomy so this was not as strongly associated with their schooling choices. While Ovink (2014) acknowledged the implications of this gendered familism as an extra burden on Latinas, they framed this as something positive, and an encouragement for greater long term educational attainment.

Espinoza (2010) found that high levels of biculturalism are a large factor in the educational advancement of students when looking at the experiences of Latina doctoral graduates. Biculturalism was defined as the ability develop identification with larger society while retaining traditions and values of the culture of origin, and feeling a sense of belonging to both (Espinoza, 2010). For example, a student's ability to balance family and school demands is partly dependent on their level of biculturalism (Espinoza, 2010). Further, the study also found that students had two ways of juggling the two worlds/cultures, either compartmentalizing or integrating the two worlds. Either way, the study found that to be able to either integrate or separate the two worlds, the student needed to have a high level of biculturalism (Espinoza, 2010). This suggests that adaptability to the new/school culture in combination with a good connection with home culture was important for the students to be able to navigate their schooling in a successful way, regardless of whether they kept the two worlds separate or integrated. 
Self- perception was found to be a predictor of academic success for Latinx high school students, where having confidence in their ability to achieve (Vick \& Packard, 2008) and the salience of becoming a college student were predictors of their efforts in school (Carter, 2006; Vick \& Packard, 2008). Also, while some students believed that education and schooling would not necessarily lead to equal work and life opportunities for racial and ethnic minority and white individuals, other students felt the opposite, and a positive relationship was found between students' perspective on the level of utility of education for success and their GPA (Carter, 2006). This is in line with the expectancy value theory, which states that in order to be motivated to achieve a goal, the individual needs to expect that engaging in specific behaviors will lead to the goal (Vick \& Packard, 2008). The students who tend to feel more positively about the utility of education and schooling are those considered "cultural straddlers", students with multiple cultural competences who are able to use varied cultural tools and resources to balance their various cultural spheres (Carter, 2006). This indicates that there is a relationship between level of biculturalism and the individual's perception of the utility of education, as well as an indirect relationship between biculturalism and success in school.

\section{Community Responses \& Resistance}

Transformation, resistance and empowerment are very important personal processes in the responses of students who have been underserved and pushed out by the school system (Solorzano \& Bernal, 2001; Matute \& Chica, 2014). Solorzano \& Bernal (2001) looked at the different experiences of student resistance of Chicana women who participated in the 1968 East Los Angeles high school walkouts and the 1993 student sit-in and hunger strike. Solorzano \& Bernal (2001) discuss oppressive school spaces as sites of resistance and empowerment, possibility and human agency. Their study showed that extracurricular experiences, as well as their own experiences of oppression in the school system led to their raised social, cultural, and 
class consciousness, and these walkouts were an "act of transformational resistance" (Solorzano \& Bernal, 2001).

Another example of community activism, Matute and Chica (2014) reported on the events from a community education forum with the Latin American community in the city of Toronto, in 2013. This forum focused on the challenges faced by the community in the education system and its purpose was to generate dialogue with parents, students, educators and community members around these challenges and possible solutions. Matute and Chica (2014) found that community collaboration as a response to the negative schooling experiences of youth and parents was one of the main discussions, and participants voiced the importance of building community, parent involvement and communication, and the importance for the stakeholders (parents, students, educators, community members) to work together to build community capacity.

\section{Research Gaps}

The literature has focused on the effects that others have on students' academic achievement (such as teachers, peers and family), personal "self-regulating" behaviours, involvement in community programs, negative experiences within school and curriculum and other external influences such as poverty. I found much of the literature was focused on individual and familial or peer influences of academic success, which puts the onus on the individual or family/home culture. There is not enough literature which focuses on the systemic aspects of early school leaving, and focusing on individuals and their families problematizes culture while normalizing the low rates of school completion for marginalized groups (in this case, Latinx students). This also reflects a foundational value of meritocracy, where school success is heavily based on "hard work" and actions taken by students and families, not the 
structural barriers of the education system (hence the neoliberal illusion of an equal playing field).

The literature used a variety of epistemological theories which guided the various studies, and in effect also steered the way information was interpreted and presented. The ecological and "multiple worlds" frameworks in this context recognize the external environmental factors that may affect academic success and therefore do not see the individual as deficient, although by focusing on their "effects" they may problematize family and culture, along with the biculturalism and familism theories. The biculturalism and familism theories acknowledge familial factors and conflicting cultural values that may create stress for students, but again they shift the blame away from the Eurocentric school system that is not able to welcome, value and utilize a variety of cultural knowledge and capital which would alleviate the stresses of feeling othered or having to juggle between worlds or cultures. The cultural wealth, community strengths and culturally responsive pedagogy frameworks take a step further in valuing the home culture and community of students, although they do not have a critical stance towards the negative educational experiences of Latinx students the way that Critical Race Theory and LatCrit Theory provide. Critical Race Theory and LatCrit Theory on the other hand both provide a good foundation to examine the discrimination and racism that students experience as well as how their racial identities affect their educational opportunities.

Aside from knowledge interpretation, it is also important to consider the various players in knowledge construction. In terms of the participants of the studies, many of the schools from which studies were conducted had either low dropout rates, focused on the high achieving students, consisted of both Latinx and Black or other marginalized students. Some of the studies also focused on the experiences of graduate students so it would be difficult to generalize the 
findings to high school students. Also, there are more studies on Black or marginalized/ immigrant students in general than specifically Latinx students, and those studies that are specific to Latinx students also tend to originate from the United States and have a high concentration of specifically Mexican American students. Indeed, an important gap in the literature is the lack of studies based in Canada/ Ontario/ Toronto: most of the literature I have found is based in the United States. Further, research that has actually involved the participation of Latinx students in Toronto are either not considered empirical studies or not published through peer reviewed journal articles.

Hence, there have not been sufficient studies with Latinx students in Toronto, looking at their schooling experience from their perspective. Students who have dropped out of school are also underrepresented in these studies. This affects what is known on this topic in the sense that little is known about the unique experiences of Latinx students in Canada, specifically the "multicultural" city of Toronto, as well as what forces some students to drop out, or be highly disengaged from their own perspective. Based on this emphasis, my research seeks to address the following questions: "What factors help or hinder success in school for Latinx students?"; and "What experiences have Latinx/students had with social workers, and how can they better support Latinx students?" 


\section{CHAPTER 3. RESEARCH DESIGN}

"Until lions have their historians, tales of the hunt shall always glorify the hunter." - African Proverb

The above proverb captures the ethnocentric and hegemonic way stories can and do operate (Lynn \& Dixson, 2013). As previously mentioned, much of the discourse surrounding early school leaving paints these students as well as their families and cultures as deficient, and generally does not focus on an in depth critical account of their experiences through the education system. For this reason, I have chosen a narrative approach for my methodology. Storytelling provides researchers a way to investigate how research participants experience the world (Webster \& Mertova, 2007), from their own perspective. Bold (2012) states that "human existence relies on synthesis and analysis of narratives" (pg. 17), hence sharing or creating stories and gathering meaning from these stories is a natural part of the human experience and is necessary for understanding our experiences and their resulting effects on ourselves.

The purpose of my chosen methodology is to look at and centre the experiences of Latinx youth that have been through high school in Toronto, and a narrative approach allows a focus on the first-hand experiences and stories of my participants (Dei, 2003; Lynn \& Dixson, 2013). Also, compared to a quantitative approach that some of the studies in the literature have taken, narrative inquiry is able to capture the complexity in research that is cultural and/or human centred (Webster \& Mertova, 2007).

Further, narrative inquiry does not attempt to objectively reconstruct people's

experiences, but rather interpret how a person perceives those experiences (Webster \& Mertova, 2007). As such, there are multiple levels of interpretation when using narrative: during the storytelling or creation of the narrative from the participant, and re-creation from the recipient 
(myself) (Bold, 2012) when sharing my findings. Bold (2012) presents this as a "danger" of using narrative as a research methodology. Although, the process of interpretation of life experiences into a narrative that is shared from my participants is the whole purpose of this research. The focus of my research is the material effects that these experiences had on my participants, hence their interpretation of their experiences is what matters. In addition, in my interpretation of the stories I gather in this study I do not attempt to be "objective", due to the acknowledgement that I bring with me a particular lens and theoretical approach as described before, Critical Race Theory, which informs the way that I interpret the information I have gathered. Nonetheless, I have tried to keep my interpretations of my participants' stories and their narratives separate, where I try to convey their stories the way they were expressed, and make it clear where I am adding my own interpretation.

CRT informs this methodology because it values the experiential knowledge of people of color and seeks to place this form of knowledge as its focus (Lynn \& Dixson, 2013). It is important to take a narrative approach, because in allowing youth to define and articulate their own problems based on their experiences, it not only gives meaning to these events but helps us understand the "dropout dilemma" from their perspective (Dei, 2003).

To address the gaps in the literature, this study focused on the Latinx student population, centering the experiences of individuals who have gone through high school in GTA and surroundings. Specifically, I explore their view on the various factors that led them to feeling disengaged from high school. To gather these narratives, my data collection method was a focus group.

\section{Participants \& Recruitment}

I received REB approval (Please see Appendix A) for this study to be conducted with former Latinx students that fit the following criteria: any individual over 19 who identifies as 
Latinx/a/o, who went to high school in the GTA. This includes individuals who both graduated or dropped out, but completed at least one year of high school. Participants could not be current students, as the aim is to hear about their experiences in hindsight through their reflections. I did not interview anyone who is younger than 19 years of age, is currently still in secondary school, does not identify as Latinx/a/o, or who never considered dropping out of school.

The criteria around school completion for the participants in this project were individuals who were disengaged during their high school years but may have dropped out or completed high school. I set up the criteria in this way to not limit the individuals that could potentially participate and to learn more about disengagement in general. My hope was that I would have some individuals who dropped out so that I could also have their experiences shared, but it was more difficult than anticipated to find these participants. As a result, all of the participants in my project have completed high school, but they have all gone through varying degrees of disengagement and nonetheless this has allowed for a rich discussion on the experiences of Latinx students who experience different oppressions in the education system. My research project began in April, 2017 with recruitment, and conducting of actual focus group and completion of transcripts beginning of May 2017. The completion of analysis and remainder of report occurred by the beginning of June. Participants were recruited through email and social media such as Facebook, through community meetings and snowball sampling (please see Appendix B and Appendix C for recruitment material).

The participants are not anonymous to me since my data collection method was a focus group. The participants are anonymous to readers of this MRP because participants have used pseudonyms during the focus group. Any further identifying information has also been removed 
from the transcripts (e.g. school names). Please see Appendix D for consent form that participants signed to be part of this study.

For my focus group, I recruited two men and two women, all whom identified as Latinx who had gone through periods of serious challenges and/or disengagement throughout their high school experience. Their ages range from 23 to 31, and they attended high school at different time periods ranging from 2000 to 2012 , so they were in high school six to seventeen years ago. One person identified as Indigenous from Mexico, and two identified as Black Latinas/ AfroLatinas and one person identified as queer. The pseudonyms chosen by the participants are: Tello, Santana, Lunar and Rodrigo.

\section{Data Collection/Storage}

I have chosen a focus group as the method of data collection to be able to facilitate a richer, deeper, dynamic conversation surrounding this issue that would be more feasible through a group discussion versus a one-on-one interview with each participant (please see Appendix E for focus group guide). A focus group is also a good fit for my investigation because it follows the values of Critical Race and LatCrit Theories, where personal experiences and "alternative" stories are shared and validated. Hence, this methodology, the combination of narrative approach and focus group, is in itself a tool for empowerment for Latinx students whose stories may not reflect the common discourse of the "dropout" Latinx student, in effect surfacing subjugated knowledges, voices and narratives. Further, through the process of sharing during the focus group, there would be a possibility of co-construction of these alternative narratives.

The data that I collected are audio files of the focus group session, transcriptions of the session from these audio files and signed consent forms. This data has been kept on an encrypted USB to protect it in case the USB is lost or stolen. Original audio files were deleted once transferred to a USB and the recording device was password protected during this process. The 
data will only be kept during the production of the resulting research paper. After completion of the research paper the data will be deleted from the USB.

\section{Data Analysis}

The data analysis method I used is thematic analysis, or thematic experience analysis.

As such, I looked for and identified themes within the narratives of my participants (Bold, 2012), and I further analyzed these themes/findings in relation to existing literature (both scholarly and community based). Once the transcription process was completed, I underwent a thematic analysis of the information/stories that were shared during the focus group and I looked for common themes throughout the different stories, also looking at themes that were not previously present and how they may inform the gaps in the literature, to answer my research questions. Further, thematic analysis assumes that most experiences encompass the relationships between people and contexts (Bold, 2012), which is why the themes I have found involve the different contexts of my participants' experiences in the education system. In the following chapter, I discuss some of the findings of the study, organized along the themes that resulted from the analysis. 


\section{CHAPTER 4: FINDINGS AND DISCUSSION}

In the following section I will briefly discuss the experience of the focus group, such as observations that I made from the group dynamic and sharing of experiences. I will then go into detail regarding the main themes that I have pulled out of the focus group discussion and discuss their reflection (or not) of the main themes found in the literature review.

All of the participants were very eager to share their experiences for my research, and I would like to note here that despite having experienced many challenges, all four participants have overcome these challenges and have flourished into people who are giving back to their community in diverse ways. I perceived the overall experience of the focus group to be a positive one. I observed that the group members were very welcoming with each other and paralleled and supported each other's experiences. In fact, there were many themes that came up which all participants shared.

The main themes that I have gathered from the focus group that echo the literature I reviewed for this MRP are: the role of teachers, staff, peers and family, access to programs and resources, community, othering and the Eurocentric school climate, cultural values and identity (to which I have also added mental health). In addition to these themes, I would like to add policing, detention and punishment, and perseverance and achievement. Within each of these themes there may be some sub-themes where I will discuss more specific issues.

\section{The Role of Teachers, Staff, Peers and Family}

I would like to note that three of the most common issue that I encountered during the focus group was the issue of streaming, othering and racism or how participants were made to feel alienated by everyone in the school, and the importance of belonging and community. These were the topics that came up constantly through each person's story, time and time again, and for 
this reason I will begin by discussing streaming, othering and racism. Another key issue surrounds community, which I will also discuss in this section.

\section{The Role of Teachers}

The most common theme that came up was the impacts that the participants' relationships with their teachers had on their learning environment, their perception of their abilities and their overall schooling experience. Tello and Lunar had similar experiences with their math teachers who questioned their inability to follow the material. In the case of Tello who attended a private Catholic school, his teacher refused to answer his questions and insisted that it was his fault because others were able to follow, and that perhaps he did not belong in the school or was not at the same level as the other students. In Lunar's case, the teacher would have to rush through the material due to the "schedule" and insisted that if she did not understand, it was her problem. In both of these cases, the teachers claimed that the sole responsibility of success in the courses were of the students, which seemed to the participants as teachers ignoring their role as teachers to be supportive in their students' learning. As a result, these experiences, along with similar attitudes from other teachers made Tello and Lunar feel stupid or doubtful of their abilities.

Teachers were not only unsupportive but also humiliating and even engaged in namecalling along with other peers. Rodrigo told a story about how one day he arrived to class around the time of the H1N1 epidemic, and after finding his desk outside the classroom the teacher proceeded to explain to him in front of the class that they (the teacher and his peers) did not feel comfortable with his presence in the class. This incident was not only extremely embarrassing to the participant but also resulted in rumors around the school that he had swine flu and therefore had bullying directed at him as well. Tello told a story about how he came to acquire the 
nickname "chancho" (which means "pig" in Spanish), and that this nickname was used to address him by his peers and eventually even his own teachers, despite knowing its meaning and that he disliked this nickname. These experiences made the participants feel hurt and alienated, and in this way their learning environment was not a healthy one conducive of learning.

On the other hand, the participants also had very positive experiences with some teachers, which also made a great impact on their schooling experience and their motivation to continue in school. Tello shared with us that one of the few supportive staff he had was a Black gym teacher who understood the negative experiences he was having in his school due to having experienced them himself in that same school. The teacher had attended this school as a student years before, and he also experienced racism in the school environment. This teacher became one of Tello's main supports in the school, and was not only someone he could talk to but also helped Tello in his fitness training goals as well as provided him with work and career opportunities in the fitness field. The result of all this was that he made Tello feel like he was good at something: “...so he helped me out a lot because he gave me an opportunity, he made me feel like I was good at something. In Lunar's case, she told us of a math teacher who was very supportive and took their time helping the students with the difficult material. The teacher was responsive to students' needs, and Lunar claims that it was because of this teacher that at this time, she actually loved math.

This demonstrates some of the ways that teachers can be supportive to students, but also the importance of having teachers who are compassionate and understanding of the various difficulties that students face in their schooling environment, such as racism. Teachers who validate the negative experiences of their students allow them to feel that systemic issues such as 
an overwhelming curriculum or unsafe environment are not their fault and their achievement is not solely dependent on them.

As seen from the experiences of my participants as well as other studies, these types of supports assist in the student's well sense of ability and motivation for school completion. This is consistent with the findings in the literature review. Matute and Chica (2014) found that lack of support in schools was a common challenge faced by Latinx students. Further, Alfaro \& UmanaTaylor (2015) found a positive relationship between academic support and academic motivation. In Lunar's experience, the attention given to each student created an environment where she felt motivated and engaged in the material. This is also similar to findings that a caring class community has a positive effect on student motivation, engagement and learning and having high expectations of your students have a positive impact on them (Adkins-Coleman's, 2010; Rodriguez, 2011; Walker, 2006).

\section{The Role of Staff}

Aside from teachers, other staff members can also have a huge impact on students. All of the participants spoke extensively about their negative experiences with guidance counselors, and mentioned being streamed by the guidance counselors, while most of the participants mentioned not having a social worker available or knowing of their presence in their school. Experiences with school principals went both ways, where some experiences were positive and some were negative. Finally, there was also some discussion around staff who take care of the school such as janitorial staff, and how their relationships with students are often overlooked.

For all participants, the guidance counselors suggested the they take a lower stream or course, or work towards a career that would require an easier route than that which the student desired. For example, in Santana's experience with her guidance counselor, she shared with them that she wanted to get into the academic stream so that she could go into college or university. 
She was advised that a better idea would be to go into applied and to perhaps do a trade or something like makeup/cosmotology, which Santana had no interest in. In Lunar's case, she was inspired to become a teacher for inner city youth, but due to her grades the guidance counselor advised to do something else. After a few ideas were turned down, they advised her to do makeup and hair as well. Tello also shared that the guidance counselor at his school also suggested that he do trades instead of following an academic stream despite not having an interest in trades. If it was not for his familial and community supports who helped him see he was capable of continuing to post-secondary education, he would have continued to take the guidance counselor's advice seriously.

A common issue highlighted in the focus group was the high expectations that the participants had on the guidance counselors, as adults that they perceived to be knowledgeable and experts on the topic of courses and pathways to certain careers. Due to seeing them as an authoritative and knowledgeable figure, participants took the opinion of their guidance counselors seriously, and as such were made to feel that they perhaps were not smart enough for their aspirations. Lunar felt that she was basically told she would not amount to anything. This experience had lasting effects on Lunar, changing her view of her abilities, and making her feel that she “...wasn't going anywhere in life.”, “...they essentially told me that I wasn't going to amount to anything." Tello also mentioned that he saw the guidance counselor as a professional who knew what he was talking about, so when the guidance counselor suggested trades, as mentioned above he at first took this very seriously. Further, Rodrigo discussed how students at his school would not go to the guidance counselors unless they really had to because there was a perception that they were very judgemental. Similarly, Santana talked about feeling disappointed after not receiving what she expected from the guidance counselor, but instead felt that they did 
not try to support her aspirations which they completely disregarded; she avoided speaking with them after this experience, as this process of choosing courses was hurtful for her:

...what was really hurtful for me that I will never forget...was when I was choosing these courses...to go to academic for the next year in grade 10, and then so first I went to the guidance counselor thinking they would give me really great guidance but that wasn't the case...I told them what I wanted to do, I wanted to take academic to get into postsecondary...my counselor was like 'I think you should really try to go for applied'...basically (he was) just trying to encourage me to do random trades that I really didn't (care) about. So that just hurt a lot and then I felt like I just didn't feel safe talking to this person so I would just avoid the guidance counselor all together after grade 9. And that was really hard because everyone would always be like, if you're having an issue or you don't know what direction to go in the school, you should be going to this person. (So) there literally was no other person.

Tello saw his principal's supportive role as limited. His principal was supportive in the sense that he would talk with Tello whenever he would get sent to the office, and he would be encouraging that things would get better. However, the principal's stance was that Tello's experiences with racism and bullying were just things that he would always have to deal with, and that he (the principal) couldn't do anything about it. Hence, the principal acted as an emotional support, but not as someone who would challenge other students' behaviours or the racism and bullying that was alive in his school. Although his support was limited, because the overall support that Tello received from other teachers and students in his school, he still counted on the principal for support.

Rodrigo's experience with his principal was similar. He felt she was a great principal but her support was limited as she stood by her staff. She was supportive if a student wanted additional academic support or wanted to start an initiative in the school, but was not able to 
confront other staff about their negative interactions with students. On the other hand, his Vice Principal was not supportive at all and actually perpetuated the racism, stereotypes and bullying that existed in his school by making racist comments and bullying certain groups of students.

Both Tello and Lunar mentioned how janitorial and other less mentioned staff can also at times provide support and positive relationships for students. Lunar mentioned that at times janitors are trusted by students more than other teachers and staff. This was definitely the case in Tello's experience, where he had formed positive relationships with janitorial and library staff who were able to provide him with opportunities for safe spaces such as the gym and library, that had a great impact on his ability to focus on his work and fitness goals without being around other students who would bother him "I made friends with the librarian and... he would leave me the key underneath the door...I would go work out and when the library was closed for everybody...I would study there till 7 or 8 and that's how I got everything done" .

With regards to social workers, only one participant had a positive experience with a social worker, while the others did not have social workers available or did not know of their presence in their school. Rodrigo shared with the group that the social worker at his school was extremely supportive with an issue that he had with a school resource officer (SRO), and she was also the only person with whom he felt comfortable talking about this issue. This was also a downfall because the social worker was only available once a week; so overall it was difficult to deal with some issues when the social worker was not around, and even when she was, it was sometimes difficult to get time with her because there were 800 students in the school. Rodrigo mentions: "...she was sort of the only person that I could talk to... so when she was not there I had no one to talk to about this issue, so for like 2 or 3 weeks it was very difficult to get support." 


\section{The Role of Peers}

In the stories told by Tello, Santana, Rodrigo and Lunar, peers played both very positive and very negative roles in their high school experience and in relation to their success as students. For some, finding peers to whom they were able to relate experientially and identify with, created a buffer from the other negativity surrounding their school experience, as well as provided a sense of community. For others, their peers were a large source of feelings of not belonging, more specifically, sources of racism, and othering.

Supportive peers were a great positive factor for Santana's schooling experience. She mentioned that meeting other queer students and the friendships she created with them were some of the things that "saved" her, as she felt that she would not have survived otherwise. Rodrigo talked about how support from other students with similar experiences as he faced helped him get through the othering and negative treatment that he received from staff and peers. Further, he also received a lot of support from his Latinx peers, as they motivated each other to attend class together, take similar courses, and join the soccer team. He also described how they would support their undocumented friends when immigration officers arrived searching for them by helping them escape from school without being seen. Despite the existence of the "Don't Ask, Don't Tell" policy, where undocumented students are supposed to be in a safe learning environment without persecution from immigration (No One Is Illegal, 2014), these incidents where school staff do not abide by the policy still happen (No One Is Illegal, 2014). This demonstrates the importance of support from peers for undocumented students, as staff are not always individuals who can be trusted when it comes to immigration issues within an overall climate and context of racism in schools.

Despite feeling welcomed by his peers in the soccer team, most of Tello's experiences with his peers were negative. As mentioned before, Tello eventually focused on working out at 
the school gym and working on his courses during hours or in areas where others would not be present, just to avoid his peers. Tello experienced a lot of bullying in the form of racist namecalling. His peers would call him things such as Mexican, border hopper and spic on a regular basis. As mentioned earlier, one of Tello's most hurtful experiences with his peers was when they started calling him "chancho" and this eventually became his nickname, based on a Mexican character from the movie Nacho Libre: "It just felt awful, I didn't have a name any more...like I'm being called 'pig' by everybody, and they knew what it meant." These were very humiliating experiences, where students even went as far as talking about his family and saying things like, “...oh look, it's chancho’s family...immigrants coming over the border something to do with Mexicans coming over the border, something to do with that, and they showed the class, everyone's laughing and stuff."

Santana experienced many tensions due to being visibly different from the rest of her school, as a Black Latina/Jamaican-Colombian in a school of mostly white folks. She had multiple experiences of invasive questions from peers, or felt isolated and ignored. When she wasn't ignored she would be stared at, or "...no one would really know what to do with you." An example of a rude, anti-Black comment from a peer was when a guy went up to her in the and said, "You're actually really pretty for a Black girl, but no offence but I would never date one". Experiences like these had lasting effects on Santana, where she felt confused about her identity and she internalized these experiences and questioned if there was something wrong with her: “...so people would always say those things and I would never forget them so they'd just make me kind of confused and wondering if the problem is with me or what's going on"

Santana attributes this anti-Black racism from peers (as well as staff) as one of the factors that hindered her success. Further, identifying as a queer person, the heteronormative and 
homophobic values of the school and her peers often made her feel like giving up. Similar to Tello, she often isolated herself to not have to deal with peers and put her energy into her work, and although she was doing better academically in grade 10 and onward, she was suffering spiritually and socially. Although she had made some other gay friends, gay individuals were outcasts in her school. Similar to the findings in Walker (2006)'s study, peers and friends sharing interests and school related goals, such as the Latinx community in Rodrigo's school who joined the soccer team together and took the same courses together, had a positive effect on Rodrigo's academic success.

Moreover, as previously suggested in Rodriguez' (2011) study, principals can make large positive impacts on students, but adjusting school programming and challenging teachers was not something that the participants in my study experienced as a response from their principals. If this is in fact due to a different job description/limitations, looking into increasing the role of principals in addressing issues that students might have with teachers would be important for student success. Finally, an improvement in staff practices and training, as suggested by Matute and Chica (2014) also seems relevant to the experiences that my participants have shared with regards to the racism, streaming and negative treatment received by teachers and other staff.

\section{The Role of Parents and Family}

In all the participants' experiences, parents and family played a very positive role, at times more supportive than that of their own school staff or teachers. For Tello, he was able to share his experiences with his parents, and although they did not always completely understand they provided support in the form of advice. Their advice was to stay out of trouble and finish school, to persevere. For Rodrigo, his parents played a large role in his placement in the academic stream when he came to high school here in Toronto, from Mexico. For Lunar, her father was a huge support in getting through the math coursework when she was doing very 
poorly. Even though her father did not always understand the material himself, he took it upon himself to learn the material to then be able to teach her. She also stated that her main form of support throughout this time came from her parents.

Parental sacrifice was also a similar theme mentioned by Lunar and Santana, and is implied in the decision of Rodrigo's parents to emigrate to Canada. Lunar stated that she battled through school because of her parents and because of the values of the importance of education that had been instilled by her parents. She understood that her parents had come to Canada and sacrificed completion of their own education in order to provide Lunar with better opportunities. Santana shared that her parents also had to sacrifice a lot, coming from Jamaica and Colombia and working hard for the wellbeing of their family; she sometimes felt the pressure to do well in school: "Knowing that my parents also immigrated here, had to sacrifice a lot and I felt sometimes the stakes were high and there was a lot of pressure on me, coming from Jamaica and Colombia and doing so much for me and my sisters to even get to this point."

Santana received support from her sister because she was also attending the same school so she was able to understand her experiences, as they were similar to hers. Her parents also gave her a lot of support by listening and tried their best to understand her, and she felt that this was something that promoted her success; they were able to push her through in difficult moments, and she felt she would not have survived if it wasn't for the love of her family. She also grew up with strong familial ties with her extended family (aunts, uncles and cousins), and this also had a positive impact on her, as they encouraged and "cheered" her on through school.

This coincides with Walker's (2006) study which found that despite parents not completing their education, the encouragement, expectations and "lost dreams" were strong motivators for students. In my study, this is equivalent to the sacrifices that the parents have 
made for the participants, and the way that these sacrifices have motivated the students to complete school. For example, Lunar's parents also did not complete their education.

\section{Access to Programs and Resources}

A program that was mentioned by both Tello and Rodrigo was SALO (Student Aid and Learning Opportunities), an after-school tutoring and mentoring program for high school students. Both participants mentioned SALO as a program that had a positive impact on their achievement in school. As Rodrigo noted: "If it wasn't for SALO and (the tutors/mentors) then I wouldn't have gotten my grades up, I wouldn't have been confident enough to get through that...so if it wasn't for that program then I would never have finished high school.” Rodrigo mentioned that attending this program along with other school and community activities helped him decide that he wanted to finish school by any means necessary.

Similarly, it was at this program that Tello came to the realization that the only way to remove himself from his negative school environment was to get through school as soon as possible; this program helped him increase his grades and motivated him to complete school despite the difficulties. For Tello, SALO positively affected his life in additional ways. First, because the volunteers of the program were university students from within his own Latinx community, he was able to see future possibilities for himself. Seeing Latinx people within academia and not images of stereotypical soccer players, gang members or boxers made him feel that he too could have a PhD or a Master's degree. Second, according to Tello, the volunteers believed in him and that he was capable of completing high school and more. More importantly, he claims they were the first to believe in him, as his usual experience at school was that his abilities were always underestimated. Once he committed to improving himself, he did not want to let them down, and for him this was the biggest factor in his success. 
Aside from SALO, Tello did not have many academic supports, as these were not provided to him from his teachers. Based on Tello's story it appears that his teachers felt that students were the ones solely responsible for their learning and success in school: “'Why don't you get this I already explained it to you? ...you're not the same level we are, I can't teach you anymore other than the way I'm teaching you, everyone else gets it but you so it's obviously your fault." The only other academic support he received was from his principal who started tutoring him when he went to Saturday detentions.

The positive impacts of SALO reflects the importance of programs and resources in the success of Latinx students, as suggested by the studies in the literature review (Behnke, Gonzalez, \& Cox, 2010; Dei, et. al., 2010; Harris \& Kiyama, 2015; Matute \& Chica, 2014; Walker, 2006). Perhaps an increase in school-based after school programs would also be beneficial, as Harris and Kiyama (2015) suggest that staff have the potential to be "institutional agents" who can assist students in navigating the school system. Behnke, Gonzalez and Cox's (2010) study which looked at the perspectives of Latinx students as to why their peers dropped out reported difficulty of school work and personal problems as two reasons. The experiences of all my participants have reflected either one or both of these as reasons for their difficult schooling experience and disengagement. As I stated in the literature review, we can see that with my participants there was also a lack of tutoring and community programs, and that when these supports were put in place they made a great positive impact (such as in Tello and Rodrigo's experiences). This also supports the finding that every student is capable of success given the right tools and resources (Dei, et al., 2010).

\section{The Role of Community}

All of the participants frequently spoke about a sense of community, belonging or feeling represented among their peers. For the most part, Tello and Lunar felt a very limited sense of 
community and belonging, whereas Santana and Rodrigo were able to experience a sense of belonging to a certain degree or in certain periods of their schooling experience.

As previously mentioned, Santana shared her feelings of not fitting in as one of the only Black/Latinx students and one of the few queer students, and hence did not fit in with the predominantly white, heteronormative values of her school: “...it was very hard because at that time I was still figuring out the things that I know now about being Black and Queer and not identifying as straight and definitely in high school there's a lot of heteronormative values, very white values and I didn't really fit into any of that." Eventually, she was able to make friends with other individuals who identified as either Latinx and/or gay and had a supportive group of friends, but even then, most of her friends were mostly white as that was the majority of the school population. Also having others around her who had similar experiences as her was helpful, such as her sister and her group of friends who mostly identified as gay, and who were also othered or treated as outcasts.

For Rodrigo, grade 11 brought a larger sense of community due to the increase in the enrollment of Latinx students who had come from other schools. He recalled that this greater sense of community increased his school attendance. He also discussed the supportive relationships that came with a sense of shared experiences, where many of his Latinx friends were also having negative experiences with peers and staff:

I was able to get support from them and that's what actually allowed me to overcome these things...there was an ability to build community from a common understanding that this was systemic and that we were just being attacked for no reason.

When Rodrigo was in grade 12, the parent committee of his school advocated for the students who were having negative experiences with SRO's in the school, and they were able to achieve 
some improvements with that issue. The SALO program was also an example of a community response, as the program was run by Latinx community members who were university students, clearly with the goal of supporting students.

As we see in the scholarship, Matute and Chica (2014) reported that building community, parent involvement and communication, and the importance of different stakeholders working together for capacity building were all points that participants of a community education forum thought were important avenues to finding solutions. The parent committee in Rodrigo's school is an example of the effectiveness of parent involvement, and school board working with parents by creating a space for them to voice and address concerns. Moreover, Tello and Rodrigo's experiences with SALO are an example of how extracurricular experiences along with their experiences of oppression can create the conditions for transformation and empowerment, where they were able to raise their consciousness (Solorzano \& Bernal, 2001) and realize their potential.

\section{Othering and Eurocentric School Climate}

\section{Othering}

Santana often spoke about the feelings of alienation and isolation that came from the othering she experienced in her school. There was a lot of segregation in her school, for example in the cafeteria there was one table with visible minorities or people of color and that table was given a racist label by her peers (the specific label has been left out to protect the anonymity/identity of the participant). These actions along with other hurtful racist comments or questions related to her race or ethnicity as a Black Latina constantly made her feel different as well as emotionally hurt. For Santana, the sexist, racist and homophobic demeanour of her peers, particularly her male peers, created compounding uncomfortable and hurtful circumstances due to her intersecting identities as a Black and Latin American queer woman; these experiences 
created a hindrance to her success. Lunar also experienced similar microaggressions from peers, for example when a student asked her if she snorted Cocaine because she was Colombian. For Tello it was generally difficult to make friends, with various failed attempts where he usually just ended up feeling ignored and segregated from everyone else. Further, he was frequently made to feel that he did not belong, not only from the isolation that he felt from his peers but he also blatantly received this message from the staff.

\section{Curriculum}

Tello described the Eurocentricity of the courses in his school, such as the History and English classes, that did not take into consideration or denied the contributions of Black, Indigenous or Latin American people, communities or historical figures. In fact, his grade 12 English teacher stated that “...Aboriginals had contributed nothing to Canada besides moccasins...". Any time that Tello attempted to talk about figures that were not Eurocentric, his teachers' responses made him feel they were not relevant or important and they would simply brush his comments off. Rodrigo had similar experiences with his history teacher, where he would avoid going to his class because of how uncomfortable he sometimes felt with the teacher's racism, as he told stories of Indigenous people from a very racist lens. As this participant identifies as Indigenous from Latin America, this “...was a very difficult experience.”

Lunar spoke about her World Issues and Political Sciences courses as two of the only courses that she truly enjoyed and did exceptionally well in, and that they started the development of her critical thinking: "There was two courses, World Issued and Political Science that really interested me and it was also the way the teacher maneuvered it, making it very critical. I think that's where the beginning of my criticalness started and I really loved those courses..." She also discussed how packed the mathematics material was, and this did not foster a friendly learning environment when the teacher had to rush through the material and did not 
have time to provide students with support: "This teacher was very much like, we have schedules, we've got to cover this, sorry if you don't understand it, that's your issue, we gotta keep going. And at that point in grade 10 if you didn't get the first chapter, you're not getting the second or third because it builds up...I got lost within the first couple of months and that was it, it was wrapped." She felt the difference, as noted previously, when one of her math teachers was able to take their time with math and this allowed for real engagement with the material and her love of math during her time in this particular class in grade 9.

All of these findings are consistent with the studies from Alfaro et. al., (2009), Carter (2006), and Rodriguez (2011). Not only can we see the negative consequences on academic success of microaggressions and discrimination coming from staff and students, but we can also see how my participants' experiences echo the voices from the discussions at the education forum (Matute \& Chica, 2014), where participants voiced stereotypes and prejudice as a common challenge. This also reflects Rodriguez's study (2011) in that negative perceptions from teachers on students leads to lowered expectations; when we link the above forms of othering and low expectations of the students with streaming from guidance counselors, they are seen as not being able to achieve in a Eurocentric school structure. The claims made by Tello and Rodrigo regarding the Eurocentric and racist curriculum and presentation of course material reflect Dei's (2010) findings that this is problematic for students because of its inability to give a well-rounded view of the world, and we see this in the way their teachers have told Indigenous stories from a white perspective and have disregarded contributions of non-white groups and individuals in history.

\section{Identity, Self-Perception and Mental Health}

Similar to Matute and Chica's (2014) findings, we also see how complex identity issues as a result of parental migration have added additional challenges for the students, in particular 
Santana and Lunar. For Lunar, as a Black Latina she did not understand her Blackness at the time of her schooling since her parents were from Colombia, and she believed the two identities to be mutually exclusive (she did not understand that there were Black Colombians or Black Latinx's). She usually felt that she did not belong because in first year there were mostly white and European descendants, and in her second year there were both African descendants and white people, so she did not see many Latinxs. Santana's experience was similar, where her identity as a Jamaican Colombian was a marker of difference in her school since her peers were mostly white as well. She was also simultaneously trying to figure out who she was and justify who she was (that she was Jamaican and Colombian). In addition to that, her identity as a queer person and not fitting in with the heteronormative and white values of the school made her experience difficult. It was not until she started meeting and making friends with other Latinx and queer people that things got better. Her experiences of racism and isolation due to her identity and not fitting in resulted in both social and spiritual suffering for her, as noted earlier, and she felt a lot of depression and anxiety from the various forms of violence that were directed at her; as she noted, she had "...a lot of struggles with self-love because everyone is just telling me to not like yourself, so that was really hard.”. This is an example of how a person's identity and the identity of their peers, as well as the intersectionalities of race and sexual orientation among others, are an important part of their schooling experiences; but further, how violence and oppression in school as a result of being different than the norm can have serious impacts on students' mental health.

In Tello's story, we saw how having the gym teacher as a mentor for his workouts/physical training and being given access to opportunities for work in this field made 
him feel like he was good at something. This teacher believed in his abilities, similar to how the tutors/mentors at the SALO program believed in his abilities:

...people in that program believed in me and they thought I could do it, and no one did that before. And all of a sudden, I was accountable to all these amazing people and I didn't want to let them down. And that's what I think was the biggest thing.

It is clear how others' perception of his abilities had an impact on his self-perception, as well as how seeing people of his community represented in academic spaces or holding positions that were outside of the typical stereotypes of Latinx people made him feel that he too was capable of academic success: “...well SALO it was just seeing people like me who weren’t soccer players or gang bangers or boxers and seeing that I could have a $\mathrm{PhD}$ or have a Masters, I could do something with my life...". SALO gave Tello the confidence and motivation to finish school.

For Lunar, her experience with the guidance counselor had a huge impact on her selfperception because she took their opinion as an authority figure of her abilities seriously. She felt that she was essentially being told that she would not amount to anything and she really started to believe that. In grade 12, due to her low grades and her low confidence, she did not put much thought into where she would apply for post-secondary because she expected to not get accepted in the first place. This negative perception of her abilities affected her motivation to complete her graduation requirement of volunteer hours and she ended up staying an additional year which turned out to be the year that she was most disengaged and actually started skipping classes and getting suspensions and detentions. The low expectations that the guidance counselor had on her really affected the expectations she had on herself as she internalized this, and we can once again see how these negative experiences can impact a student's mental health. 
These findings are highly correlated with the findings from Vick and Packard (2008) and Carter (2006), where self-perception was identified as a predictor of academic success for Latinx high school students. Specifically, having confidence in their ability to achieve (Vick \& Packard, 2008) and the salience of becoming a college student were predictors of their efforts in school (Carter, 2006; Vick \& Packard, 2008). There are two parts to this, both which have been reflected in the stories of my participants. First, whether or not they perceived themselves as capable of completing school affected their motivation to complete school; second, being able to meet others from their own community who were in university or college also increased the motivation to complete school.

\section{Policing, Detention and Punishment}

Another theme that was common with all participants was experience with policing, detention and punishment. Whether it was detention, suspension, policing of uniform infractions, being kicked out of class or harassed by the security resource officers (SRO's, or police). This had various detrimental effects on the participants' self-perception as well as their desire to be in a space where they felt unsafe, that their friends were unsafe or where they felt they were constantly picked on and policed. Hence, this had a negative effect on their engagement in school, not only because of the time lost from class but because of the desire to avoid school and class. The most common reasons for detention were uniform infractions, reactions to bullying or “aggressive behavior" and skipping class. According to all the participants, they skipped class because they felt disengaged from class.

For example, Rodrigo shared that in his school, the SRO's would go to the last period classes to escort students to detention, or they would support the hall monitors in doing this. Therefore, students would avoid last period to avoid being escorted to detention. He also shared 
that he was not able to trust them or build a positive relationship with SROs. Another example of policing was when his school created a sign in sheet system to track the times that students would arrive and leave class that would have to be signed by the teacher with additional comments on their performance in class, which would then be reviewed by guidance counselor, vice principal or principal. Further, this sign in sheet system was only used with certain students, and Rodrigo was not sure what the criteria was, but teachers could give out this sheet to students at their own discretion. Similarly, many students would not wear proper uniform but only some would get in trouble for it. He also shared that there was a teacher in his school who would give out detentions all the time, at his own discretion, and he was known by students as giving out detentions constantly. He also felt that detentions were "useless, dumb", that unlike some schools who provided academic support during detention, his did not and it was like jail, they were not productive and were a waste of time and constant detentions are one of the things that push students out of school.

In Tello's case, most of his detentions were due to physical aggression or "overreactions" (getting loud or angry) to the bullying he faced from his peers. While his peers were not penalized for racist comments or bullying, Tello was usually the one sent to the office or to detention or suspension for standing up for himself: “...that's the reason I would be sent to the office, they'd call me Mexican, border hopper, spic, beaner, wetback, and if I said anything or did anything...that I'd get louder or get mad then they'd just send me to the office..." These comments and bullying were acknowledged by school staff as "just words". In addition, punishment as a response to his behavior also resulted in loss of other supports or opportunities. For example, at one point Tello was on "expulsion watch" and they would make him write tests at different times than other students, which would coincide with his soccer games, and this 
would not be accommodated so he was put in the position to choose between writing his tests or participating the soccer team/games which put him membership of the team in jeopardy. Overall, he felt that detention was not productive but a waste of time, and that a punishment approach should not be used on students as it does not improve anything. There was only one exception when he would go to Saturday detention and the principal would tutor him. In this case Tello would willingly attend his Saturday detention to receive tutoring, which reflects that he was dedicated and wanted to learn.

For Santana, she felt over-policed and disproportionately policed for her uniform, constantly being sent to the office for minor uniform infractions, while other students in her class who also committed the same uniform infractions were not policed as much. “...it was literally if my shoe laces had just a bit of white and they were supposed to be black I'd get sent straight to the office... and at the same time in that same class, there would be another white girl who's wearing brown shoes and completely out of uniform and they would just leave here there." Santana would be asked to stay in the office all day or parents would be called and told that she would have to change her clothes in order to return to class, or she would stay in detention all day. Both her and her sister felt policed, and Santana attributes this to the fact that they were really visible (or visibly different). She also felt that she was picked on by teachers who would go out of their way to call her through the intercom while she was in another class.

Lunar's experience with detentions mainly began when she returned to school for an additional year and was already disengaged. She skipped class and was getting detentions and suspensions and constantly being called to the office. In her experience, this only worsened her view of herself and she still did not see a future for herself. 


\section{Perseverance and Achievement}

Despite the racism, bullying and stereotypes endured by my participants from staff, teachers and peers, all of the participants talked about their determination and perseverance, and were able to achieve many things. With the support of the gym teacher, Tello dedicated himself to a workout program that helped to improve his physical and mental condition, and positively impacted his desire and ability to focus on his school work. Despite other peers who had attempted this same program and gave up, he did not. Further, his dedication to finish school and focus on his courses was demonstrated when he set himself up with his workout and study schedule such as studying during breaks and free time, and found places to study where he would not be bothered by his peers. His abilities and desire were there, but the supportive individuals around him provided him with these opportunities.

Despite dropping out of school for a semester, Rodrigo also showed a lot of determination when he decided he wanted to finish school, as he completed 17 courses in one year, through regular school, night school, summer school, and even George Brown for a semester. Santana isolated herself from peers and instead put her energy into her work, and doing well in school was her form of survival. The sacrifices her parents made to give her and her sisters a better future also put a lot of pressure on her to do well in school because she felt at times that the stakes were high. She was determined to prove those who questioned her abilities wrong, and the anger she eventually started feelings towards those in her school that caused her harm slowly turned into activism.

With Lunar, despite feeling disengaged and having to stay back another year in high school, she was able to graduate. All of the participants graduated despite their difficult experiences and this can be attributed to a combination of their hard work and the supports that 
they had. All of the participants and their families felt that education was important, and this is what pushed them through. In fact, Lunar mentioned that she battled through school because of her parents and because she understood that her parents had sacrificed their own education for her to have a better life in Canada:

I think I just battled through it because of my parents. Even at that young of an age I was still able to understand that my parents didn't finish their education and sacrificed to come here and because of those values instilled that education is very important, that is the only thing that pushed me through.

Despite being turned down by her guidance counselor for wanting to be a teacher, and her feelings of inadequacy, she eventually continued on to do a program in community and justice services in post-secondary school after taking a personality/career test that matched her with community and justice services.

We can see that all of the participants had the capacity to finish high school and had the motivation and dedication to do so once they felt that they were capable of doing so. All of the participants continued on to post-secondary school and three out of the four participants have completed or are currently completing a Master's program. Taking these and other findings discussed in this chapter, I discuss various implications for research, policy and practice in the final chapter of this MRP. 


\section{CHAPTER 5: IMPLICATIONS AND CONCLUSION}

In the present study, I aimed to shed more light on the issue of school disengagement with Latinx students in high school, by sharing the narratives of four former Latinx high school students. Several themes that arose closely reflected those found in the literature, such as the positive and negative influences of teachers, staff, peers and family; positive impact of programs and resources; the negative impacts of othering and a Eurocentric curriculum; the importance of community; and the importance of identity and self-perception. Other topics also arose, including the effects on mental health; constant policing, detention and punishment; and perseverance and achievement. In particular, racism and streaming were both common experiences among all of the participants. I would like to once again reference the words of Dei et. al., (2010), that students are capable of success given the right tools and resources. Resources can be extended to human relationships as supportive resources, and as we see in this study, having access to support from school agents, friends and family are all important for student success. On the other hand, the racism and Eurocentricity present in schools has damaging effects on the selfperception, well-being and resulting academic performance of Latinx students. With these findings, I will make some suggestions for research, policy and social work practice.

As noted earlier, this study was conducted with students who did complete high school. As such, I believe that it is important that more research is done with individuals who have been pushed out of high school to truly capture the factors and events that lead them to the decision of leaving. In terms of the role of social workers, more research can be done specifically on the interactions between social workers in schools and the Latinx community, as well as the interactions with other types of social workers, such as those working in community agencies and mental health centres. Such research could assist us in further understanding the impacts on 
and needs of Latinx students, and how social workers have been/can continue to support in the other areas of their life that also affect their schooling. It is also important to further look at the specific after school programs, such as SALO, that have had positive impacts on Latinx students and explore the particularities of these programs that are helpful to students.

In terms of policy, there are a few points I would like to mention. First, as seen in reports that focus on student and community voices, student voice is fuelling the need for policy change (Matute \& Chica, 2014; Schugurensky, Mantilla, \& Serrano, 2009). Based on the experiences of my participants, there have not been enough consequences for racism, or the mental, emotional and spiritual abuse, whereas physical violence is usually given attention and results in detentions/suspensions. In addition, the consequences of perpetrating this mental, emotional and spiritual abuse should also be applied on all members of a school, not just students, as teachers and other staff were noted to be perpetrators of bullying as well. My participants got in trouble for getting into fights or not having a proper uniform, yet there did not seem to be many, if any, consequences for those who were bullying them constantly.

Additionally, there is a need to move away from punishments like detention and suspensions. Based on the experiences of my participants, these were not an effective method for change as these were, in their own words, a "waste of time", and did not address the root cause of the problem. In addition, the time spent in detention or suspension is actually more time away from class/school which will only hinder a student who may already be behind in coursework. There should also be more regulation on those who have the authority to give out detentions or consequences, to prevent picking on specific students, which is an experience that some of my participants shared and related back to racism. 
Streaming was an issue that was mentioned by all of my participants, and had a negative impact on all of them. There needs to be more regulation and accountability in terms of the type of advice given to students from guidance counselors, especially when certain populations tend to be advised more than others to follow lower academic streams, which limits their future opportunities. It is also important to take this issue more seriously based on the psychological effects it has on students to be told that they do not have the capacity to reach their academic/career goals simply because of low grades, instead of being offered support or motivation. School boards should look further into the practice (even unintentional) of streaming, and looking into ways to truly implement no streaming and ways to assess compliance of this policy from schools and staff. It is clear that what is required is a change to school policies, the curriculum, and increases in government funding for more teachers and support staff as well as improved mandatory cultural sensitivity and anti-racism training for all staff, not just teachers.

Finally, all of the participants mentioned that they had limited exposure to social workers, either because they were not present, their presence was very limited or they did not know of their presence in their school. Based on the stories of all the participants, it seems that all of them could have benefited from speaking with a supportive school social worker. In the case of one participant, the social worker was able to support him but her presence was limited and therefore her support was also limited. Considering the daily violence that occurs in schools and how certain populations such as Latinx students tend to be targeted, it would be beneficial for social workers to have a larger presence inside schools to be able to provide more consistent support and deal with the complex issues that students are experiencing daily.

It is my hope that this exploration has served to further confirm the need for changing the discourse on disengaged Latinx students, to reflect the many ways they are being 
underserved, overlooked, ignored, marginalized and pushed out of schools. From a social work perspective, we need to recognize the resilience of these students. It is also important to take a wholistic approach to this issue, and realize that the overall improvement of the schooling experience and academic success of Latinx students relies on significant changes at the government, school/social work policy and individual staff level. 


\section{APPENDICES}

\section{Appendix A: REB Approval}

\section{Ryerson \\ University \\ Research Ethics Board}

\section{To: Catalina Calero School of Social Work}

Re: REB 2016-440: Latinx/a/o Students in Toronto and their Educational Experiences Date: February 2, 2017

\section{Dear Catalina Calero,}

The review of your protocol REB File REB 2016-440 is now complete. The project has been approved for a one year period. Please note that before proceeding with your project, compliance with other required University approvals/certifications, institutional requirements, or governmental authorizations may be required.

This approval may be extended after one year upon request. Please be advised that if the project is not renewed, approval will expire and no more research involving humans may take place. If this is a funded project, access to research funds may also be affected.

Please note that REB approval policies require that you adhere strictly to the protocol as last reviewed by the REB and that any modifications must be approved by the Board before they can be implemented. Adverse or unexpected events must be reported to the REB as soon as possible with an indication from the Principal Investigator as to how, in the view of the Principal Investigator, these events affect the continuation of the protocol.

Finally, if research subjects are in the care of a health facility, at a school, or other institution or community organization, it is the responsibility of the Principal Investigator to ensure that the ethical guidelines and approvals of those facilities or institutions are obtained and filed with the REB prior to the initiation of any research.

Please quote your REB file number (REB 2016-440) on future correspondence.

Congratulations and best of luck in conducting your research.

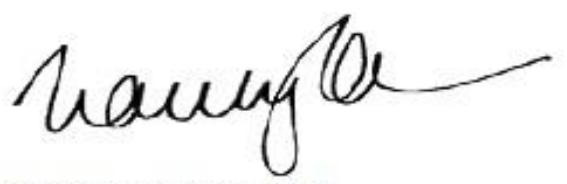

Dr. Nancy Walton, $\mathrm{PhD}$

(A) Co-Chair

Ryerson Research Ethics Board

416-212-4952

nwalton@ryerson.ca

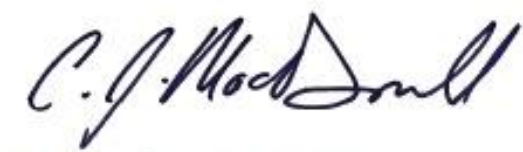

Dr. Chris Macdonald, $\mathrm{PhD}$

(A) Co-Chair

Ryerson Research Ethics Board

416-979-5000 ext. 6903

chris.macdonald@ryerson.ca 


\section{Ryerson \\ University}

\section{Appendix B: Recruitment Flyer}

\section{RESEARCH PARTICIPANTS NEEDED}

Are you an individual who identifies as Latinx/a/o, who went through high school in the GTA, and either graduated or "dropped out"? Would you like to share your experiences attending school?

What: A focus group where you will be able to share your story with regards to your experience in the school system. Focus group will last about one and a half to two hours.

Where: Potential location is a private library room at Ryerson University. Further details will be given upon being selected.

Light refreshments will be provided.

Who: To participate you must meet the following criteria:

- Currently out of highschool

- Attended public or catholic high school in Toronto, Peel, Halton, Durham or York (graduating not required)

- Self identifies as Latinx/a/o

- Have completed at least grade 9

- Either "dropped out" or almost did/seriously considered it

- 19 years or older

You will be reimbursed for TTC costs with two tokens.

For more information or to participate, please email Catalina Calero at

\section{ccalero@,ryerson.ca}

This study is being conducted by a graduate student as requirement for program completion, and has been approved by the Ryerson Research Ethics Board.

Research supervisor, Samantha Wehbi, can be reached at swehbi@,ryerson.ca 


\section{Appendix C: Recruitment Email}

\section{Ryerson}

University

\section{RESEARCH PARTICIPANTS NEEDED}

Are you an individual who identifies as Latinx/a/o, who went through high school in the GTA, and either graduated or "dropped out"? Would you like to share your experiences attending school?

What: A focus group where you will be able to share your story with regards to your experience in the school system. Focus group will last about one and a half to two hours.

Where: Potential location is a private library room at Ryerson University. Further details will be given upon being selected.

Light refreshments will be provided.

Who: To participate you must meet the following criteria:

- Currently out of highschool

- Attended public or catholic high school in Toronto, Peel, Halton, Durham or York (graduating not required)

- Self identifies as Latinx/a/o

- Have completed at least grade 9

- Either "dropped out" or almost/seriously considered it

- 19 years or older

You will be reimbursed for TTC costs with two tokens.

For more information or to participate, please email Catalina Calero at

\section{ccalero@ryerson.ca}

This study is being conducted by a graduate student as requirement for program completion, and has been approved by the Ryerson Research Ethics Board.

Research supervisor, Samantha Wehbi, can be reached at swehbi@ryerson.ca

Note: Please respond within 7 days of receiving this flyer 


\section{Appendix D: Consent Agreement}

\section{Ryerson \\ University}

You are being invited to participate in a focus group for a research study. A focus group is a guided discussion conducted by a facilitator (in this case, myself), in a circular group setting, with the aim of providing each participant an opportunity to share their experiences on the specified topic for the purpose of gaining some insight on that topic.

Please read this consent form so that you understand what your participation will involve. Before you consent to participate, please ask any questions to be sure you understand what your participation will involve.

\section{STUDY: Latinx/a/o Students in Toronto and their Educational Experiences}

INVESTIGATORS: This research study is being conducted by Catalina Calero, Social Work student from the School of Social Work at Ryerson University. The supervisor for this research is Samantha Wehbi, at Ryerson University.

If you have any questions or concerns about the research, please feel free to contact Catalina Calero at ccalero@ryerson.ca

PURPOSE OF THE STUDY: This study is designed to explore the educational experiences of Latinx/a/o students from the GTA. Specifically, it will focus on the experiences that helped former students complete high school or that led them to drop out of high school, as well as experiences with Social Workers in schools. The number of participants being recruited is five. Potential participants must identify as Latinx/a/o, have gone through secondary school in the GTA and either dropped out or completed school. If they dropped out they must have completed at least one year of high school before dropping out. Participants will be 19 or older. The results of this study will contribute to my Major Research Project as part of my Masters of Social Work program.

WHAT YOU WILL BE ASKED TO DO: If you volunteer to participate in this study, you will be asked to do the following:

\section{1) ARRANGE A TIME TO MEET}

I will choose a time that is convenient for everyone, using an online doodle poll.

2) REVIEW INTERVIEW GUIDE

You will be given an interview guide the day that the focus group will be held, and will be given time to review the questions before the focus group begins. A couple of questions will include:

What are some factors that you would say helped your success in school? 
What are some factors that you feel led to your decision to drop out (if applicable)?

Can you share some experiences you have had with social workers in your high school?

Can you give some feedback on how social workers can better support Latinx/a/o students in high school?

\section{3) ATTEND THE FOCUS GROUP}

This will happen on the day that is chosen based on everyone's availability, using doodle poll. The focus group will last between one to two hours, depending how much people have to share.

\section{4) ACCESS TO FINAL RESEARCH PAPER}

The final paper will be available online once complete, all participants will be given instructions on how to access the paper if they so choose.

\section{POTENTIAL BENEFITS:}

This study will add to the academic literature on the schooling experiences of Latinx/a/o students. The results may also be used in academic or community presentations and articles. Further, there is a potential benefit for individuals in having an opportunity to share their story and build community/connections with others who may have similar experiences.

I cannot guarantee, however, that you will receive any personal benefits from participating in this study.

\section{WHAT ARE THE POTENTIAL RISKS TO YOU AS A PARTICIPANT?}

The potential risk to participants is low. The possible risks or discomforts that a participant may encounter as a result of participation are as follows:

- Feeling upset/triggered/uncomfortable while answering questions

- Being exposed or embarrassed, potential loss of privacy and damage to reputation due to the topics that will be discussed

- People will be stating their names before they speak to keep track of it during the transcribing portion of the research process, but they do not have to state last names or any other identifying information. They will only be known by those who are participating in the focus group.

The following are provisions to address these potential issues or steps taken to reduce the chance of these risks:

- Support will be provided during the focus group, and make sure that the space is a supportive and welcoming space by talking about this with all participants before commencement of focus group session

- I will also provide all participants with information for resources in the community at the beginning of the focus group

- Most people will come with the understanding that people's experiences are varied as has been explained in the purpose of my research. 
- Individuals do not have to disclose any information they do not feel comfortable disclosing, so they have some control over being embarrassed, loss of privacy, reputation, etc.

- During the transcription process, I will make sure to include fake names for people

- As will be mentioned later in this form, and will be discussed before the focus group begins, everyone is asked to keep the information they learn about others confidential

\section{CONFIDENTIALITY:}

Confidentiality of records identifying participants will be maintained. Throughout the focus group, you will be asked to use pseudonyms (fake names). The audio recording will be erased after transcription; the transcription documents will be kept on an encrypted USB. The transcripts will be deleted after the completion of the study.

The recording will be done with a password protected phone or recording device and then transferred to a computer where it can be saved to the USB. It will then be deleted from the device. During the process of writing the research paper, the transcripts will be stored on the encrypted USB. I will be the only person to have access to any information from the study for the whole process of the project; my supervisor will only have access to excerpts with no identifying information.

By participating in the focus group you are also committing to keeping all information about others confidential

\section{INCENTIVES FOR PARTICIPATION:}

The participants will not be paid to participate in the study. Although, there will be light snacks provided.

\section{COSTS TO PARTICIPATION:}

Reimbursement will be offered for transit costs in the form of TTC tokens ( 2 per person) An attempt will be made to have the focus group where there is free parking available.

\section{COMPENSATION FOR INJURY:}

By agreeing to participate in this research, you are not giving up or waiving any legal right in the event that you are harmed during the research.

\section{VOLUNTARY PARTICIPATION AND WITHDRAWAL:}

Participation in this study is completely voluntary. You can choose whether to be in this study or not. If any question makes you uncomfortable, you can skip that question. You may stop participating at any time and you will still be provided the reimbursements described above. If you choose to stop participating, you may also choose to not have your data included in the study. In this case please let the investigator know by end of May 2017. Your choice of whether or not to participate will not influence your future relations with Ryerson University or the investigator Catalina Calero or her supervisor involved in the research. 
QUESTIONS ABOUT THE STUDY: If you have any questions about the research now, please ask. If you have questions later about the research, you may contact:

Catalina Calero

MSW student

ccalero@,ryerson.ca

Research Supervisor:

Samantha Wehbi

(416) 979-5000 ext.6221

swehbi@ryerson.ca

This study has been reviewed by the Ryerson University Research Ethics Board. If you have questions regarding your rights as a participant in this study please contact:

Research Ethics Board

c/o Office of the Vice President, Research and Innovation

Ryerson University

350 Victoria Street

Toronto, ON M5B 2K3

416-979-5042

rebchair@,ryerson.ca 


\section{LATINX/A/O STUDENTS IN TORONTO AND THEIR EDUCATIONAL EXPERIENCES}

\section{CONFIRMATION OF AGREEMENT:}

Your signature below indicates that you have read the information in this agreement and have had a chance to ask any questions you have about the study. Your signature also indicates that you agree to participate in the study and have been told that you can change your mind and withdraw your consent to participate at any time. You have been given a copy of this agreement.

You have been told that by signing this consent agreement you are not giving up any of your legal rights.

Name of Participant (please print)

$\overline{\text { Signature of Participant }} \quad \overline{\text { Date }}$

I agree to keep all information I learn about others in the focus group confidential.

Signature of Participant

Date

I agree to be audio-recorded for the purposes of this study. I understand how these recordings will be stored and destroyed.

Date 


\section{Appendix E: Focus Group Interview Guide}

* Please note that you will be asked to use a pseudonym during the focus group for confidentiality purposes.

\section{Opening question(s)}

Can you tell me a little bit about your high school experience? Academically? Socially?

For example, you can tell me about an experience that highlights how the academic or social aspects of school were for you.

\section{Factors}

What factors do you feel helped your success in school and affected your decision to stay in school?

What factors do you feel hindered your success in school and/or affected your decision to leave school (if applicable)

\section{Experiences with Social Workers}

Please describe any experiences you have had with social workers

\section{Suggestions}

Do you have any suggestions regarding how social workers can better support Latinx/a/o students? 


\section{REFERENCE LIST}

Adkins-Coleman, T. A. (2010). "I'm not afraid to come into your world": Case Studies of teachers facilitating engagement in urban high school English classrooms. The Journal of Negro Education, 79(1), 41-53.

Ahmed, S. (2007). 'You end up doing the document rather than doing the doing': Diversity, Race, Equality and the Politics of documentation. Ethnic and Racial Studies, 30(4), 590-609.

Alfaro, E. C., \& Umana-Taylor, A. J. (2015). The longitudinal relation between academic support and Latino students' academic motivation. Hispanic Journal of Behavioral Sciences, 37(3), 319-341. doi:10.1177/0739986315586565

Alfaro, et. al., (2009). Latino adolescents' academic success: The role of discrimination, academic motivation, and gender. Journal of Adolescence, 32, 941-962.

Altonji, J. G., \& Doraszelski, U. (2005). the role of permanent income and demographics in black/white differences in wealth. Journal of Human Resources, 40(1), 1-30.

Anisef, P., Brown, R. S., Phythian, K., Sweet, R., \& Walters, D. (2010). early school leaving among immigrants in Toronto secondary schools. Canadian Review of Sociology, 47(2), 103-128.

Behnke, A., Gonzalez, L., \& Cox, R. (2010). Latino students in new arrival states: factors and services to prevent youth from dropping out. Hispanic Journal of Behavioral Sciences, $32(3), 385-409$.

Bold, C. (2012). Using Narrative in Research. Lodon: Sage.

Carter, P. L. (2006). Straddling boundaries: identity, culture and school. Sociology of Education, 79(4), 304-328. 
Crenshaw, K., Gotanda, N., Peller, G., \& Kendall, T. (Eds.). (1995). Critical race theory: the key writings that formed the movement. New York: The New Press.

Dei, G. J. (2003). Schooling and the dilemma of youth disengagement. McGill Journal of Education, 38(2), 241-256.

Dei, G. J. (2010). The possibilities of new/counter and alternative visions of schooling. English Quarterly, 41(3-4), 113-132.

Dei, G. S., Butler, A., Gulzar, C., Kola-Olusanya, A., Opini, B., Thomas, R., \& Wagner, A. (2010). Learning to succeed: The challenges and possibilities of educational development for all. New York: Teneo Press

Espinoza, R. (2010). The good daughter dilemma: Latinas managing family and school demands. Journal of Hispanic Higher Education, 9(4), 317-330. doi:10.1177/1538192710380919

Harris, D., \& Kiyama, J. (2015). The role of school and community based programs in aiding Latina/o high school persistence. Education and Urban Society, 47(2), 182-206.

Ladson-Billings, G. (2007). Pushing past the achievement gap: an essay on the language of deficit. The Journal of Negro Education, 76(3), 316-323

Lynn, M., \& Dixson, A. D. (Eds.). (2013). Handbook of critical race theory in education. New York: Routledge.

Matute, A. A., \& Chica, D. (2014). Community voices, community action: Latin American education network 2013 community education forum. Latin American Encounters, 2, 2539.

Museus, S. (2013). Asian American students in higher education. New York: Routledge. 
No One Is Illegal. (2014). Recommendations for the Toronto district school board: Best practices in providing access to education for students with precarious immigration status. Toronto

Ovink, S. M. (2014). "They always call me an investment": Gendered familism and Latina/o college pathways. Gender \& Society, 28(2), 265-288. doi:DOI: $10.1177 / 0891243213508308$

Reichard, Raquel (2015, August 29). Why we say Latinx: Trans \& gender nonconforming people explain. Latina. Retrieved from http://www.latina.com/lifestyle/our-issues/why-we-say$\underline{\text { latinx-trans-gender-non-conforming-people-explain }}$

Rodriguez, M. A. (2011). "But they just can’t do it": Reconciling teacher expectations of Latino students. Journal of Cases in Educational Leadership, 15(1), 25-31

Schugurensky, D. (2009). The educational experience of Spanish-Speaking youth: The Brown Report and the forty percent question. In D. Schugurensky, D. Mantilla, \& J. F. Serrano (Eds.), Four in ten: Spanish-speaking youth and early school leaving in Toronto (pp. 310). Toronto: Latin American Research Education and Development Network, OISE

Schugurensky, D., Mantilla, D., \& Serrano, J. F. (2009). Four in ten: Spanish-Speaking youth and early school leaving in Toronto. Toronto: Latin American Research Education and Development Network, OISE

Shankar, J., Ip, E., Khalema, E., Couture, J., Tan, S., \& Al, E. (2013). Education as a social determinant of health: issues facing Indigenous and visible minority students in postsecondary education in Western Canada. International Journal of Environmental Research and Public Health, 10, 3908-3929. 
Solorzano, D. G., \& Bernal, D. D. (2001). Examining transformational resistance through a critical race and Latcrit theory framework: Chicana and Chicano students in an urban context. Urban Education, 36, 308-342. doi:DOI: 10.1177/0042085901363002

Solorzano, D. G., \& Yosso, T. J. (2001). From racial stereotyping and deficit discourse toward a critical race theory in teacher education. Multicultural Education, 9(1), 2-8.

Vick, R. M., \& Packard, B. W. (2008). Academic success strategy use among community-active urban Hispanic adolescents. Hispanic Journal of Behavioural Sciences, 30(4), 463-480. doi: $10.1177 / 0739986308322913$

Walker, E. N. (2006). Urban high school students' academic communities and their effecrs on mathematics success. American Educational Research Journal, 43(1), 43-73.

Waxman, H. C., Padron, Y. N., \& Garcia, A. (2007). Educational issues and effective practices for Hispanic Students. In S. J. Paik, E. Gordon, \& H. J. Walberg (Eds.), Issues in children's and families' lives: narrowing the achievement gap: strategies for educating Latino, Black, and Asian Students (pp. 131-151). New York: Springer.

Webster, L. \& Mertova, P. (2007). Using narrative inquiry as a research method: An introduction to using critical event narrative analysis in research on learning and teaching. New York: Routledge. 